\title{
Bilateral anterior ischaemic optic neuropathy associated with optic disc drusen and systemic hypotension
}

\author{
CLIFFORD MICHAELSON,' MYLES BEHRENS, ${ }^{2}$ AND JEFFREY ODEL ${ }^{2}$
}

From the ${ }^{1}$ Departments of Ophthalmology and Neurology, Boston University Medical Center, and the ${ }^{2}$ Edward $S$ Harkness Eye Institute, Columbia Presbyterian Medical Center, New York

SUMMARY We report a case of bilateral anterior ischaemic optic neuropathy in a 23-year-old woman which was probably attributable to optic disc drusen and systemic hypotension related to peritoneal dialysis for renal failure.

Non-arteritic anterior ischaemic optic neuropathy (AION) ${ }^{1-3}$ appears to be the result of obstruction of axoplasmic flow owing to ischaemia, leading to a cascading effect via further small vessel compromise $^{45}$ in the setting of underlying disc crowding. ${ }^{6-8}$ It has been reported in patients, some relatively young, with drusen of the optic nerve head. ${ }^{10}{ }^{10}$ We report on a young woman with systemic hypotension who had optic disc drusen and developed bilateral AION while on home peritoneal dialysis.

\section{Case report}

A 23-year-old white female noticed on awakening the painless loss of inferotemporal vision in the left eye in late February 1986. On 14 March her visual acuity was $20 / 20$ on the right and $20 / 25+3$, with marked relative afferent pupillary defect and marked constriction of visual field on the left. There were drusen of both optic discs, with swelling of the left. A CT scan of the head and orbits was considered normal.

On 22 May her visual acuity was $20 / 20$ in each eye without relative afferent pupillary defect. The right disc pale and elevated, the left flat and mildly atrophic. In early June she awoke with marked dimunition of vision in the right eye and was referred to our Neuro-ophthalmology Clinic on 20 June.

She had been on haemodialysis for chronic renal

Correspondence to Clifford Michaelson, MD, Gundersen Eye Center, Doctors' Office Building, 720 Harrison Avenue-10th Floor, Boston, MA 02118, USA. failure following post-streptococcal glomerulonephritis until 1984 and on peritoneal dialysis thereafter. She was chronically hypotensive, with blood pressure $52 / 38$ and $62 / 38 \mathrm{~mm} \mathrm{Hg}$ at clinic visits in January and February 1986. An oral contraceptive (Ortho-Novum, norethisterone with ethinyloestradiol) taken for approximately four years was discontinued when visual symptoms first developed. Her visual acuity was finger counting at $2-3$ feet $(60-90 \mathrm{~cm})$, with hand motion only superotemporally in the right eye, and $20 / 20+3$ with the field concentrically constricted on tangent screen in the left eye. Colour plates (AO-HRR): 0/6 OD, 6/6 OS.

External, motility, and slit-lamp examinations gave normal results. Tension by applanation was 16 in each eye. Her pupils were sluggish, with a marked right relative afferent defect. There were bilateral disc drusen, with right more than left optic atrophy, and diffuse thinning of the nerve fibre layer (Figs. 1 and 2). Calcification was evident in both optic nerve heads on review of her orbital CT scan (Fig. 3).

\section{Discussion}

Various factors may have contributed to apparent bilateral consecutive AION in our patient, with optic disc oedema preceding visual loss by weeks in the second eye, as may occur. ${ }^{2}$ "She had optic disc drusen in both eyes, which have been associated with transient visual obscurations ${ }^{12}$ and permanent visual loss, ${ }^{13}$ including AION. ${ }^{914}$ Preceding transient visual 


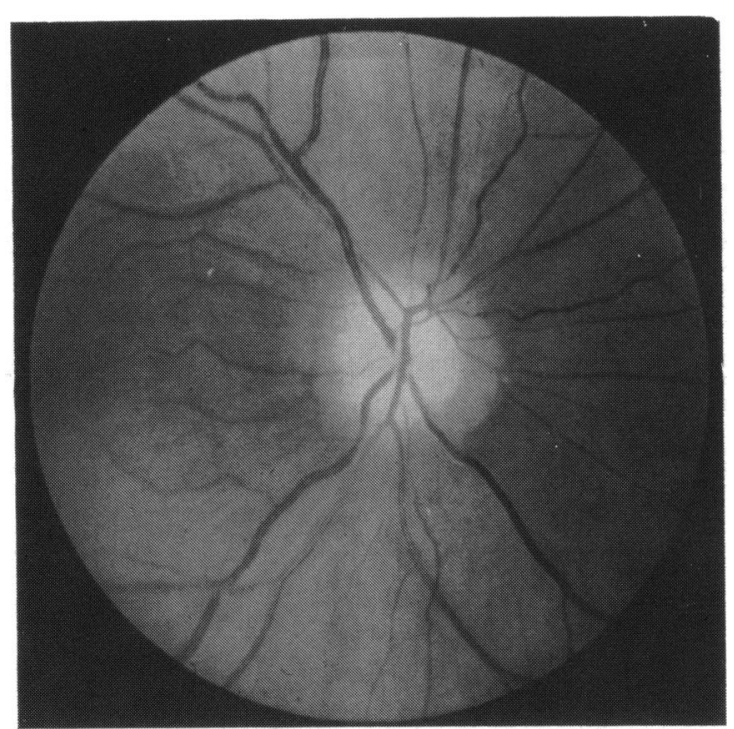

Fig. 1 Appearance of right optic disc on 20 June 1986.

loss" and recurrent episodes of AION have been reported. ${ }^{15}$ Hypotension has been suggested, in addition to increase of intraocular pressure, ${ }^{16}$ as a basis for the frequent finding of visual loss in AION, as in our patient, on awakening. Impairment of autoregulation of optic nerve perfusion may have been an additional factor in our patient, who was chronically hypotensive. This was postulated by Taylor et al. ${ }^{17}$ in his cases of AION following sudden reduction in systemic blood pressure in chronically

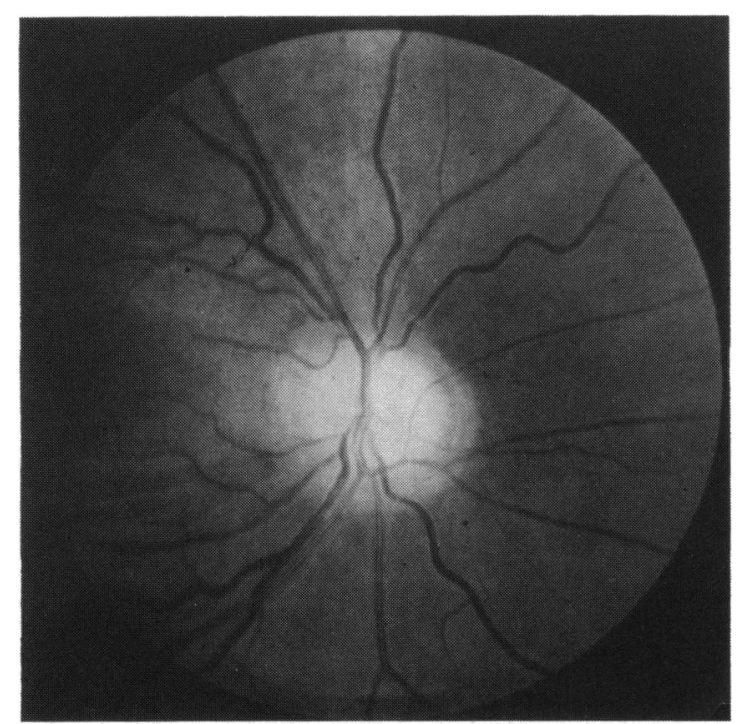

Fig. 2 Appearance of left optic disc on 20 June 1986.

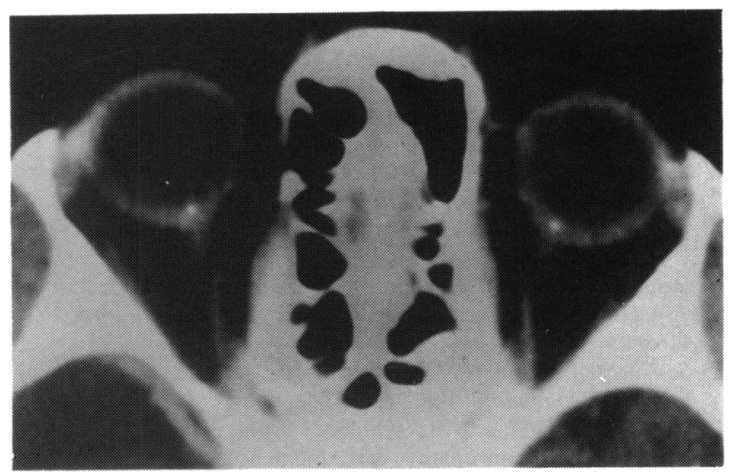

Fig. 3 Orbital CT scan in March 1986 showing bilateral optic nerve head calcification.

hypertensive children with disc swelling. Drusen, through mass effect, may have raised the intraneural tissue pressure, ${ }^{12}$ leading to greater susceptibility to ischaemia. The crowded discs reported with drusen, ${ }^{15} 18$ as in our patient and others," may have been another factor. Increased circulating vasoconstricting agents may exacerbate hypoperfusion in the setting of hypotension in posthaemorrhagic AION ${ }^{19}$ and in AION following cardiopulmonary bypass..$^{2111}$ Peritoneal dialysis may have contributed to her AION, as suggested by the association with haemodialysis ${ }^{162}$ together with hypotension"2 and intraocular pressure elevation ${ }^{2324}$ in that setting. Oral contraceptives, reported to be associated with various forms of vaso-occlusive disease (including possibly $\mathrm{AION}^{25}$ ) even months after their cessation, seem unlikely to be of significance in our patient, though not entirely excluded.

\section{References}

1 Hayreh SS. Anterior ischemic optic neuropathy. Berlin: Springer, 1975.

2 Boghen DR, Glaser JS. Ischemic optic neuropathy. Brain 1975: 98: $689-708$.

3 Miller NR. Walsh and Hoyt's clinical neuro-ophthalmology. 4th ed. Volume I. Baltimore: Williams and Wilkins, 1982: 1: 219-21.

4 McLeod D, Marshall J, Kohner EM. Role of axoplasmic transport in the pathophysiology of ischaemic disc swelling. Br J Ophthalmol 1980; 64: 247-61.

5 Beck RW, Servais GE, Hayreh SS. Anterior ischemic optic neuropathy. IX. Cup-to-disc ratio and its role in pathogenesis. Ophthalmology 1987: 94: 1503-8.

6 Beck RW. Savino PJ, Repka MX, Schatz NJ, Sergott RC. Optic disc structure in anterior ischemic optic neuropathy. Ophthalmology 1984; 91: 1334-7.

7 Feit RH, Tomsak R, Ellenberger C Jr. Structural factors in the pathogenesis of ischemic optic neuropathy. Am J Ophthalmol 1984; 98: $105-8$.

8 Doro S, Lessell S. Cup-disc ratio and ischemic optic neuropathy. Arch Ophthalmol 1985: 103: 1143-9.

9 Gittinger JW, Lessell S, Bondar RL. Ischemic optic neuropathy associated with optic disc drusen. J Clin Neuro-ophthalmol 1984: 4: $79-84$. 
10 Karel I, Otradovec J, Peleska M. Fluorescein angiography in circulatory disturbances in drusen of the optic disc. Ophtholmologica 1972; 164: 449-62.

11 Hayreh SS. Anterior ischemic optic neuropathy. V. Optic disc edema as early sign. Arch Ophthalmol 1981: 99: 1030-40.

12 Sadun AA, Currie JN, Lessell S. Transient visual obscurations with elevated discs. Ann Neurol 1984: 16: 489-94.

13 Lorentzen SE. Drusen of the optic disc. Acta Ophthalmol (Kbh) 1966; 90 (suppl).

14 Beck RW, Corbett JJ, Thompson HS, Sergott RC. Decreased visual acuity from optic disc drusen. Arch Ophthalmol 1985; 103: $1155-9$.

15 Sarkies NJC, Sanders MD. Optic disc drusen and episodic visual loss. Br J Ophthalmol 1987: 71: 537-9.

16 Beri M, Klugman MR, Kohler JA, Hayreh SS. Anterior ischemic optic neuropathy. VII. Incidence of bilaterality and various influencing factors. Ophthalmology 1987; 94: 1020-8.

17 Taylor D, Ramsay J, Day S, Dillon M. Infarction of the optic nerve head in children with accelerated hypertension. Br J Ophthalmol 1981; 65: 153-60.

18 Mullie MA, Sanders MD. Scleral canal size and optic nerve head drusen. Am J Opthalmol 1985: 99: 356-9.

19 Hayreh SS. Anterior ischemic optic neuropathy. VIII. Clinical features and pathogenesis of post-hemorrhagic amaurosis. Ophthalmology 1987: 94: 1488-502.

20 Larkin DFP, Connolly P, Magner JB, Wood AE, Eustace P. Intraocular pressure during cardiopulmonary bypass. Br J Ophthalmol 1987: 71: 177-80.

21 Larkin DFP, Wood AE, Neligan M, Eustace P. Ischaemic optic neuropathy complicating cardiopulmonary bypass. Br J Ophthalmol 1987: 71: 344-7.

22 Servilla KS, Groggel GC. AION as a complication of hemodialysis. Am J Kidney Dis 1986; 8: 61-3.

23 Sitpyra V. Holmes JH, Ellis PP. Intraocular pressure changes during artificial kidney therapy. Arch Ophthalmol 1964: 72: 62631 .

24 Watson AG, Greenwood WR. Studies on the intraocular pressure during hemodialysis. Can J Ophthalmol 1966; 1: 301-7.

25 Varga M. Recent experiences on the ophthalmologic complications of oral contraceptives. Ann Ophthalmol 1976; 10: 925-34.

Accepted for publication 24 February 1989. 